\title{
Interrelationship among blood pressure, intraocular pressure, and life-style in middle-aged and older Japanese residents
}

\author{
Masao Yoshida ${ }^{1^{*}}$, Shinichiro Take ${ }^{1,2}$, Mamoru Ishikawa ${ }^{1,3}, K^{2}$ anae Karita ${ }^{1}$, Akatsuki Kokaze ${ }^{1,4}$, \\ Matsuko Harada ${ }^{1,5}$, Hideki Ohno ${ }^{1}$ \\ ${ }^{1}$ Department of Public Health, Kyorin University School of Medicine, Tokyo, Japan; \\ *Corresponding Author: yohhy@,ks.kyorin-u.ac.jp \\ ${ }^{2}$ Saitama Kaisei Hospital, Saitama, Japan \\ ${ }^{3}$ Mito Red Cross Hospital, Ibaraki, Japan \\ ${ }^{4}$ Department of Public Health, Showa University School of Medicine, Tokyo, Japan \\ ${ }^{5}$ Department of Living Science, Teikyo Junior College, Tokyo, Japan \\ Received 26 June 2013; revised 26 July 2013; accepted 1 August 2013 \\ Copyright (C) 2013 Masao Yoshida et al. This is an open access article distributed under the Creative Commons Attribution License, \\ which permits unrestricted use, distribution, and reproduction in any medium, provided the original work is properly cited.
}

\section{ABSTRACT}

To clarify the interrelationship among blood pressure (BP), intraocular pressure (IOP), and lifestyle related factors, a cross-sectional study was conducted. This epidemiological study analyzed health examination data obtained between 2001 and 2004 from 1113 Japanese individuals, ranging in age 28 to 79 years, who had not undergone any ocular surgery or medical treatment for hypertension, ocular hypertension, and glaucoma. The association of systolic and diastolic BP (SBP and DBP), and life-style related factors such as body mass index (BMI), drinking, smoking, and exercise habits with IOP were evaluated by multiple regression analyses and analyses of covariance. The results of this study showed that SBP, DBP, and BMI had a significantly positive association with IOP in both sexes. In men, the number of cigarette smoking per day was also positively related to IOP $(P<0.05)$. In respect to the interrelationship among $B P, I O P$, and life-style related factors, it was found that smoking was associated with high IOP, especially with "high BP accompanied by high IOP". The results of this study suggested that prohibition of smoking in addition to management of BP and BMI might be important to Japanese patients with open-angle glaucoma or ocular hypertension as they have a higher incidence of normal tension glaucoma than Europeans and Americans.
Keywords: Intraocular Pressure; Blood Pressure; Life-Style; Epidemiology; Glaucoma

\section{INTRODUCTION}

Glaucoma is the second leading cause of blindness worldwide. It is estimated that the number of people with glaucoma will be 80 million in 2020 , and more than $70 \%$ of those will have open-angle glaucoma (OAG) [1]. Ocular hypertension, which is usually defined to be in traocular pressure (IOP) higher than normal, IOP $>21 \mathrm{mmHg}$, in the absence of optic nerve damage or visual field loss [2], is one of the major risk factors for the development of OAG [3]. Several studies have reported that relatively high IOP can cause optic-nerve damage and visual-field abnormalities, even if it is within the normal range $[4,5]$. High IOP can also affect the progression of visual-field defects in patients with $\mathrm{OAG}$, particularly those with normal tension glaucoma (NTG) [6,7].

Many cross-sectional epidemiological studies have investigated the risk factors associated with elevated IOP. Although positive associations have been found between IOP and blood pressure (BP), and several life-style related factors such as body mass index (BMI), drinking, smoking, and exercise habits [8-18], most of these reports were conducted in Western countries. Few epidemiological studies have examined this relationship in a Japanese population $[16,18]$. Up to the present, there have been no studies investigating the interrelationship among BP, IOP, and life-style related factors. Moreover, the role of life-style related factors as a cause for "high 
BP accompanied by high IOP" remains obscure. Therefore, in the present study, we attempted to clarify whether high BP was associated with elevated IOP, and whether there were some particular life-style related factors specific to "high BP accompanied by high IOP". We analyzed health examination data from middle-aged and older Japanese residents in a prefectural capital close to Tokyo. The results of this study might contribute to preventing the progression of IOP-related optic-nerve damage and visual-field defects.

\section{METHODS}

\subsection{Subjects}

A total of 1,320 residents of the Ibaraki prefecture, Japan, underwent an annual health examination between April 2001 and March 2004 at a general hospital in Mito, which is the capital city of the prefecture. From this initial group, 1113 individuals (829 men and 284 women), ranging in age from 28 to 79 years, who had not undergone any ocular surgery or medical treatment for hypertension, ocular hypertension, and glaucoma, were selected for cross-sectional analysis.

This study was conducted in accordance with the Declaration of Helsinki of the World Medical Association and was approved by the human ethics review committees of Mito Red Cross Hospital and Kyorin University School of Medicine in Japan.

\subsection{Health Examination}

The health examination consisted of a questionnaire that assessed demographic and lifestyle-related factors, along with the following measurements and tests: height, weight, BP, IOP, hematological and serum biochemistry, chest X-rays, electrocardiography, and fundus photography. All subjects were requested not to consume any food or alcohol after 21:00 $\mathrm{h}$ on the day before the examination.

The topics covered in the questionnaire included age, marital status, occupation, residence, current status and past history of medication, family medical history, drinking history, smoking history and number of cigarette smoking per day, and exercise habits. Alcohol consumption was classified into the following four categories: never or seldom, several times per month, several times per week, and everyday. BP was measured with a sphygmomanometer using the right arm; two consecutive measurements were taken after subjects had rested in a sitting position for at least $5 \mathrm{~min}$. IOP was measured using a non-contact tonometer (NT-3000, Nidek, Japan) and three consecutive measurements were taken per eye.

\subsection{Statistical Analyses}

SBP and DBP values for each subject were calculated as the mean of two measurements. For IOP, the mean of three measurements was calculated for each eye; however, as there was a strong correlation $(r=0.84)$ between the mean IOPs of the right and left eyes in each individual, the mean of these two values was used as a single measure of IOP. The associations of age with IOP, SBP, DBP, and BMI - calculated as weight $(\mathrm{kg}) /$ height squared $\left(\mathrm{m}^{2}\right)$ - were determined by comparing the mean values of these four parameters among four age groups $(<40$ years, 40 - 49 years, $50-59$ years, and $\geq 60$ years) by gender, using the Bonferroni multiple-comparison method [19]. The Student's $t$-test was used to analyze differences in the mean IOP, SBP, DBP, and BMI between the two sexes by age group.

To analyze the associations of BP and life-style related factors with IOP, first, the partial regression coefficients and the standardized partial regression coefficients for IOP of the following independent variables were determined by multiple-regression analysis: SBP (model 1), DBP (model 2), and BMI, alcohol consumption (never or seldom $=0$; several times per month $=1$; several times per week $=2$; everyday $=3$ ), number of cigarettes smoking per day, and regular exercise (no $=0$; yes $=1)$. Second, to analyze the interrelationship among BP, IOP, and life-style related factors, the adjusted mean of the eligible etiologic factors, calculated by analysis of covariance, were compared between the four groups classified by BP and IOP levels; Group A: hypertensives (high-normal BP or hypertension) with high IOP (highnormal IOP or ocular hypertension), Group B: hypertensives without high IOP, Group C: normotensives with high IOP, Group D: normotensives without high IOP. The definition of hypertensives, normotensives, and high IOP in the present study was as follows: hypertensives (SBP $>130 \mathrm{mmHg}$ and/or DBP $>85 \mathrm{mmHg}$ ), normotensives (SBP $<130 \mathrm{mmHg}$ and DBP $<85 \mathrm{mmHg}$ ), and high IOP (IOP $>15 \mathrm{mmHg}$ ). All analyses were conducted using the SAS statistical software package, version 8.2. [20].

\section{RESULTS}

The relationships between age and IOP, SBP, DBP, and BMI are shown in Table 1. The mean IOP was highest in the $<40$ age group for both sexes. In both sexes, the highest mean SBP, DBP, and BMI values were found in the age group of $\geq 60,50-59$, and 50 - 59, respectively. All parameters measured were significantly higher in men than in women (IOP, $\mathrm{P}<0.05$; SBP, DBP, and BMI, $\mathrm{P}<0.01$ ). The Bonferroni multiple-comparison analysis revealed that the mean IOP was significantly lower in the $\geq 60$ age group than in the $<40$ age group in both sexes ( $P$ $<0.05$ ).

Table 2 shows the partial regression coefficients and the standardized partial regression coefficients of SBP, 
Table 1. Relationships between age and IOP, SBP, DBP, and BMI by sex.

\begin{tabular}{|c|c|c|c|c|}
\hline \multirow{2}{*}{$\begin{array}{c}\text { Age Group } \\
\text { (Number of Subjects) }\end{array}$} & \multicolumn{4}{|c|}{ Mean \pm SD } \\
\hline & $\begin{array}{c}\text { IOP } \\
(\mathrm{mmHg})\end{array}$ & $\begin{array}{c}\text { SBP } \\
(\mathrm{mmHg})\end{array}$ & $\begin{array}{c}\text { DBP } \\
(\mathrm{mmHg})\end{array}$ & $\begin{array}{c}\text { BMI } \\
\left(\mathrm{kg} / \mathrm{m}^{2}\right)\end{array}$ \\
\hline \multicolumn{5}{|l|}{ MEN } \\
\hline$<40(135)$ & $14.2 \pm 2.4^{\mathrm{d}}$ & $119.1 \pm 13.6^{\mathrm{c}, \mathrm{d}}$ & $71.0 \pm 9.4^{\mathrm{c}}$ & $23.2 \pm 2.7$ \\
\hline $40-49(225)$ & $13.9 \pm 2.3$ & $122.2 \pm 13.4^{\mathrm{c}, \mathrm{d}}$ & $71.6 \pm 8.7^{\mathrm{c}}$ & $23.3 \pm 2.4$ \\
\hline $50-59(322)$ & $13.8 \pm 2.7$ & $127.2 \pm 14.1^{\mathrm{a}, \mathrm{b}, \mathrm{d}}$ & $75.6 \pm 9.1^{\mathrm{a}, \mathrm{b}}$ & $23.4 \pm 2.5$ \\
\hline$\geq 60(147)$ & $13.3 \pm 2.4^{\mathrm{a}}$ & $134.2 \pm 16.4^{\mathrm{a}, \mathrm{b}, \mathrm{c}}$ & $73.8 \pm 9.5$ & $22.2 \pm 2.4$ \\
\hline Total (829) & $14.0 \pm 2.5$ & $124.9 \pm 14.5$ & $73.6 \pm 9.1$ & $23.3 \pm 2.4$ \\
\hline \multicolumn{5}{|l|}{ WOMEN } \\
\hline$<40(75)$ & $14.0 \pm 2.5^{\mathrm{d}}$ & $111.4 \pm 12.4^{\mathrm{c}, \mathrm{d}^{*}}$ & $65.7 \pm 7.3^{\mathrm{c} * *}$ & $21.9 \pm 3.1$ \\
\hline $40-49(90)$ & $13.6 \pm 2.3$ & $118.5 \pm 12.6$ & $69.5 \pm 7.9$ & $22.1 \pm 2.8^{* *}$ \\
\hline $50-59(106)$ & $13.6 \pm 2.8$ & $123.1 \pm 12.9^{\mathrm{a}^{*}}$ & $71.5 \pm 8.1^{\mathrm{a}^{* *}}$ & $22.9 \pm 2.9$ \\
\hline$\geq 60(73)$ & $13.2 \pm 2.4^{\mathrm{a}}$ & $127.3 \pm 15.8^{\mathrm{a}}$ & $69.5 \pm 8.2$ & $21.5 \pm 2.5$ \\
\hline Total (284) & $13.7 \pm 2.6^{*}$ & $121.0 \pm 13.9^{* *}$ & $70.0 \pm 8.0^{* *}$ & $22.3 \pm 2.8^{* *}$ \\
\hline
\end{tabular}

IOP, intraocular pressure; SBP, systolic blood pressure; DBP, diastolic blood, pressure; BMI, body mass index. Significant differences at the 0.05 level on the basis of Bonferroni multiple comparison: ${ }^{a}$ versus age group $<40 ;{ }^{b}$ versus age group $40-49$; ${ }^{c}$ versus age group $50-59$; ${ }^{d}$ versus age group $\geq 60$. P values for difference between males and females: ${ }^{*} \mathrm{P}<0.05 ;{ }^{* *} \mathrm{P}<0.01$.

Table 2. Partial and standardized partial regression coefficients of SBP, DBP, BMI, alcohol consumption, number of cigarette smoking per day, and regular exercise for IOP according to a multiple regression analysis.

\begin{tabular}{|c|c|c|c|c|c|c|}
\hline \multirow[t]{2}{*}{ Variables $^{\dagger}$} & \multicolumn{2}{|c|}{$\begin{array}{l}\text { Partial } \\
\text { Regression Coefficients }\end{array}$} & \multicolumn{2}{|c|}{$\begin{array}{c}\text { Standardized Partial } \\
\text { Regression Coefficients }\end{array}$} & \multicolumn{2}{|c|}{$P$ Value } \\
\hline & MEN & WOMEN & MEN & WOMEN & MEN & WOMEN \\
\hline \multicolumn{7}{|l|}{ Model 1} \\
\hline $\mathrm{SBP}(\mathrm{mmHg})^{*}$ & 0.055 & 0.056 & 0.205 & 0.209 & $<0.01$ & 0.03 \\
\hline BMI $\left(\mathrm{kg} / \mathrm{m}^{2}\right)$ & 0.143 & 0.174 & 0.144 & 0.190 & $<0.01$ & 0.03 \\
\hline Alcohol consumption & 0.301 & 0.264 & 0.125 & 0.097 & 0.09 & 0.30 \\
\hline Cigarette smoking & 0.032 & 0.066 & 0.143 & 0.155 & 0.03 & 0.17 \\
\hline Regular exercise & 0.129 & -0.210 & 0.024 & -0.048 & 0.52 & 0.46 \\
\hline \multicolumn{7}{|l|}{ Model 2} \\
\hline $\mathrm{DBP}(\mathrm{mmHg})^{*}$ & 0.082 & 0.087 & 0.264 & 0.278 & $<0.01$ & 0.01 \\
\hline BMI $\left(\mathrm{kg} / \mathrm{m}^{2}\right)$ & 0.133 & 0.153 & 0.135 & 0.166 & 0.03 & 0.06 \\
\hline Alcohol consumption & 0.290 & 0.235 & 0.118 & 0.086 & 0.06 & 0.22 \\
\hline Cigarette smoking & 0.032 & 0.069 & 0.149 & 0.160 & 0.02 & 0.13 \\
\hline Regular exercise & 0.140 & -0.258 & 0.028 & -0.060 & 0.44 & 0.35 \\
\hline
\end{tabular}

IOP, intraocular pressure; SBP, systolic blood pressure; DBP, diastolic blood pressure; BMI, body mass index. ${ }^{\dagger}$ Age, SBP (model 1) or DBP (model 2), alcohol consumption (never or seldom $=0$; several times per month $=1$; several times per week $=2$; everyday $=3$ ), number of cigarettes consumed per day, and regular exercise $($ no $=0$; yes $=1)$ were added as independent variables. ${ }^{*}$ Age, BMI, alcohol consumption (never or seldom $=0$; several times per month $=1$; several times per week $=2$; everyday $=3$ ), number of cigarettes consumed per day, and regular exercise $($ no $=0$; yes $=1)$ were added as independent variables.

DBP, BMI, alcohol consumption, number of cigarettes smoking per day, and regular exercise for IOP according to multiple-regression analyses, including SBP (model 1) or DBP (model 2) as independent variables. After adjusting for other independent variables, with the exception of corresponding variables, SBP, DBP, BMI, and number of cigarette smoking per day had a significant positive association with IOP in men $(\mathrm{P}<0.05)$. In women also, SBP, DBP, and BMI had a significant positive association with IOP $(\mathrm{P}<0.05$ with the exception of $\mathrm{BMI}$ in model 2 for women where $\mathrm{P}=0.06$ ).

In Table 3, the adjusted mean levels of SBP, DBP, BMI, alcohol consumption, number of cigarette smoking per day, and regular exercise obtained by analyses of 
Table 3. Adjusted mean levels of BMI, alcohol consumption, number of cigarette smoking per day, and regular exercise by the four groups classified by BP and IOP.

\begin{tabular}{|c|c|c|c|c|}
\hline & BMI & $\begin{array}{c}\text { Alcohol } \\
\text { consumption }\end{array}$ & Cigarette smoking & Regular exercise \\
\hline \multicolumn{5}{|l|}{ Group A $(\mathrm{N}=121)$} \\
\hline Hypertensives $^{\dagger}$ with high IOP* & $23.9 \pm 0.3^{\mathrm{dd}}$ & $2.2 \pm 0.2^{\mathrm{dd}}$ & $11.3 \pm 1.4^{\mathrm{d}, \mathrm{BB}}$ & $0.31 \pm 0.05$ \\
\hline \multicolumn{5}{|l|}{ Group B $(\mathrm{N}=180)$} \\
\hline Hypertensives $^{\dagger}$ without high IOP $^{*}$ & $24.0 \pm 0.2^{\mathrm{dd}}$ & $1.8 \pm 0.2$ & $5.2 \pm 1.1^{\mathrm{d}}$ & $0.27 \pm 0.04^{\mathrm{d}}$ \\
\hline \multicolumn{5}{|l|}{ Group C (N = 213) } \\
\hline Normotensives ${ }^{\hbar}$ with high IOP ${ }^{*}$ & $23.7 \pm 0.2^{\mathrm{d}}$ & $2.1 \pm 0.1^{\mathrm{dd}}$ & $8.7 \pm 0.9^{\mathrm{B}}$ & $0.38 \pm 0.04^{\mathrm{B}}$ \\
\hline \multicolumn{5}{|l|}{ Group D $(\mathrm{N}=599)$} \\
\hline Normotensives $^{\ddagger}$ without high IOP* & $22.5 \pm 0.1^{\mathrm{BB}}$ & $1.6 \pm 0.1$ & $7.9 \pm 0.3^{\mathrm{B}}$ & $0.40 \pm 0.02^{\mathrm{B}}$ \\
\hline
\end{tabular}

BMI, body mass index; SBP, systolic blood pressure; DBP, diastolic blood pressure; IOP, intraocular pressure. ${ }^{\dagger}$ High-normal BP or hypertension, SBP $\geq 130$ $\mathrm{mmHg}$ and/or DBP $\geq 85 \mathrm{mmHg}$. ${ }^{\ddagger} \mathrm{SBP}<130 \mathrm{mmHg}$ and DBP $<85 \mathrm{mmHg}$. High-normal IOP or ocular hypertension, IOP $>15 \mathrm{mmHg}$. Statistical significance of the difference from the value in Group $\mathrm{D}$ : ${ }^{\mathrm{D}} \mathrm{p}<0.05 ;{ }^{\mathrm{dd}} \mathrm{P}<0.01$. Statistical significance of the difference from the value in Group $\mathrm{B}$ : ${ }^{\mathrm{B}} \mathrm{P}<0.05$; ${ }^{\mathrm{BB}} \mathrm{P}<0.01$. All the values are adjusted for sex $(\operatorname{men}=1$, women $=2)$, age, and the other four variables except for the corresponding variable of BMI, alcohol consumption (never or seldom $=0$; several times per month $=1$; several times per week $=2$; everyday $=3$ ), number of cigarettes consumed per day, and regular exercise (no $=0$, yes $=1$ ).

covariance are compared among four groups classified by BP and IOP levels. The high BMI was found to be associated with each of high BP and high IOP, being not specifically associated with "high BP accompanied by high IOP". Alcohol intake appeared to be more closely related to high IOP rather than high $\mathrm{BP}$. It was found that smoking was associated with high IOP, especially with "high BP accompanied by high IOP", although high BP was in itself inversely related to smoking when the IOP was not high. Regular exercise was more frequently found in normotensives than in hypertensives.

\section{DISCUSSION}

The mean IOP across the group as a whole, measured using a non-contact tonometer, was $14.0 \pm 2.5 \mathrm{mmHg}$ for men and $13.7 \pm 2.6 \mathrm{mmHg}$ for women; the mean IOP was significantly higher in men than in women $(\mathrm{P}<$ 0.05). In both sexes, the mean IOP decreased with age and subjects $\geq 60$ years of age showed the lowest mean IOP. Several previous studies of Europeans and Americans have reported an increase in IOP after the age of 40 years and a decrease in IOP among elderly populations, although IOP was also found to decrease with age in Asian populations [16,21,22].

In the present study, a positive association with IOP was observed for SBP, DBP, and BMI in both men and women, as reported in previous epidemiological studies [8-18]. Many such studies have observed a positive association of IOP with SBP [8-17] and BMI [8,15-18], and others have found a positive association between IOP and both SBP and DBP [12-14,16,17].

Previous reports on the mechanism of the BP-IOP association $[23,24]$ have suggested that high BP, especially elevated SBP, might elevate IOP by increasing ultrafil- tration of the aqueous humor through the elevation of ciliary artery pressure. Studies of the BMI-IOP association have also indicated that this association might be caused by a reduction in aqueous-humor outflow caused by elevated intraorbital pressure associated with excessive intraorbital fatty tissue, or by an increase in the outflow resistance of the episcleral vein due to an increase in blood viscosity associated with weight gain $[8,15,25]$.

Our study showed that smoking was significantly associated with elevated IOP in men. This significant positive association was not found in women. However, because of the relatively small sample size in women (14.1\%) compared to those in men $(41.6 \%)$, this association may not have reached a statistically significant level in women. Other studies have also reported a positive association of smoking with IOP [15,26,27]. However, the interrelationship among BP, IOP, and smoking habit remains controversial. $\mathrm{Wu}$ [15] and Lee [27] reported that both current smoking history and SBP were positively associated with IOP. On the other hand, Morgan [26] observed that ocular hypertensives smoked more heavily and had more long-term smoking history than controls, but were less likely to have had treatment for raised systemic BP than controls.

Up to the present, there have been no studies investigating the interrelationship among BP, IOP, and life-style related factors such as BMI, drinking, smoking, and exercise habits. Moreover, the role of life-style related factors as a cause for "high BP accompanied by high IOP" remains obscure. Therefore, we attempted to clarify whether there were some particular life-style related factors specific to "high BP accompanied by high IOP". From the results of the analyses of covariance on the interrelationship among BP, IOP, and life-style re- 
lated factors, it was found that smoking was associated with high IOP, especially with "high BP accompanied by high IOP”, although high BP was in itself inversely related to smoking when the IOP was not high. To our knowledge, our study offers the first report on the interrelationship among BP, IOP, and smoking. Smoking might play some potential roles in the development of hypertension accompanied by high intraocular pressure. Further analyses are required for reliable evidence of the interrelationship among cigarette consumption, BP, and IOP.

According to the nationwide glaucoma survey in Japan [28] and the US Collaborative Normal-Tension Glaucoma Study [29,30], it was clarified that the prevalence of visual-field abnormalities gradually increased over $15 \mathrm{mmHg}$ of IOP and that the progression of visual-field defects was significantly reduced among the NTG group, which showed a $30 \%$ decrease in IOP compared with the untreated control group. Therefore, prohibition of smoking in addition to management of BP and BMI might be especially important to Japanese patients with OAG or ocular hypertension as they have a higher incidence of NTG than Europeans and Americans.

\section{ACKNOWLEDGEMENTS}

This study was supported by a Grant-in-Aid from the Ministry of Education, Culture, Sports, Science and Technology of Japan (No. 22790570).

\section{REFERENCES}

[1] Quigley, H.A. and Broman, A.T. (2006) The number of people with glaucoma worldwide in 2010 and 2020. British Journal of Ophthalmology, 90, 262-267. http://dx.doi.org/10.1136/bjo.2005.081224

[2] Leske, M.C. (1983) The Malik, A.S., Boyko, O., Atkar, N. and Young, W.F. (2001) The epidemiology of open-angle glaucoma: A review. American Journal of Epidemiology, 118, 166-191.

[3] Musch, D.C., Gillespie, B.W., Lichter, P.R., Niziol, L.M. and Janz, N.K.; CIGTS Study Investigators (2009) Visual field progression in the Collaborative Initial Glaucoma Treatment Study the impact of treatment and other baseline factors. Ophthalmology, 116, 200-207.

http://dx.doi.org/10.1016/j.ophtha.2008.08.051

[4] Jonas, J.B., Gusek, G.C. and Naumann, G.O. (1988) Optic disk morphometry in high myopia. Graefe's Archive for Clinical and Experimental Ophthalmology, 226, 587-590. http://dx.doi.org/10.1007/BF02169209

[5] Suzuki, Y., Shirato, S., Adachi, M. and Hamada, C. (1999) Risk factors for the progression of treated primary openangle glaucoma: A multivariate life-table analysis. Graefe's Archive for Clinical and Experimental Ophthalmology, 237, 463-467. http://dx.doi.org/10.1007/s004170050262

[6] Suzuki, Y., Iwase, A., Araie, M., Yamamoto, T., Abe, H.,
Shirato, S., et al.; Tajimi Study Group (2006) Risk factors for open-angle glaucoma: In Japanese population: The Tajimi Study. Ophthalmology, 113, 1613-1617. http://dx.doi.org/10.1016/i.ophtha.2006.03.059

[7] Leske, M.C., Heijl, A., Hyman, L., Bengtsson, B., Dong, L. and Yang, Z.; EMGT Group (2007) Predictors of longterm progression in the early manifest glaucoma trial. Ophthalmology, 114, 1965-1972.

http://dx.doi.org/10.1016/j.ophtha.2007.03.016

[8] Dielemans, I., Vingerling, J.R., Algra, D., Hofman, A., Grobbee, D.E. and de Jong, P.T. (1995) Primary openangle glaucoma. Intraocular pressure and systemic blood pressure in the general elderly population. The Rotterdam Study. Ophthalmology, 102, 54-60.

[9] Tielsch, J.M., Katz, J., Sommer, A., Quigley, H.A. and Javitt, J.C. (1995) Hypertension, perfusion pressure, and primary open-angle glaucoma. A population-based assessment. Archives of Ophthalmology, 113, 216-221

http://dx.doi.org/10.1001/archopht.1995.01100020100038

[10] Leske, M.C., Connell, A.M.S., Wu, S.Y., Hyman, L.G. and Schachat, A.P. (1995) Risk factors for open-angle Glaucoma: The Barbados eye study. Archives of Ophthalmology, 113, 918-924.

http://dx.doi.org/10.1001/archopht.1995.01100070092031

[11] Bonomi, L., Marchini, G., Marraffa, M., Bernardi, P., Morbio, R. and Varotto, A. (2000) Vascular risk factor for primary open angle glaucoma: The Enga-Neumarkt Study. Ophthalmology, 107, 1287-1293. http://dx.doi.org/10.1016/S0161-6420(00)00138-X

[12] Mitchell, P., Lee, A.J., Rochtchina, E. and Wang, J.J. (2004) Open-angle glaucoma and systemic hypertension. The Blue Mountains Eye Study. Journal of Glaucoma, 13, 319-326. http://dx.doi.org/10.1097/00061198-200408000-00010

[13] Xu, L., Wang, H., Wang, Y. and Jonas, J.B. (2007) Intraocular pressure correlated with arterial blood pressure: The Beijing eye study. American Journal of Ophthalmology, 144, 461-462. http://dx.doi.org/10.1016/j.ajo.2007.05.013

[14] Klein, B.E., Klein, R. and Linton, K.L. (1992) Intraocular pressure in an American community: The Beaver Dam Eye Study. Investigative Ophthalmology \& Visual Science, 33, 2224-2228.

[15] Wu, S.Y. and Leske, M.C. (1997) Associations with intraocular pressure in the Barbados Eye Study. Archives of Ophthalmology, 115, 1572-1576.

http://dx.doi.org/10.1001/archopht.1997.01100160742012

[16] Kawase, K., Tomidokoro, A., Araie, M., Iwase, A. and Yamamoto, T.; Tajimi Study Group, Japan Glaucoma Society (2008) Ocular and systemic factors related to intraocular pressure in Japanese adults: the Tajimi study. British Journal of Ophthalmology, 92, 1175-1179. http://dx.doi.org/10.1136/bjo.2007.128819

[17] Nangia, V., Bhojwani, K., Matin, A., Sinha, A. and Jonas, J.B. (2009) Intraocular pressure and arterial blood pressure: The Central India eye and medical study. Archives of Ophthalmology, 127, 339-340. http://dx.doi.org/10.1001/archophthalmol.2008.618

[18] Mori, K., Ando, F., Nomura, H., Sato, Y. and Shimokata, 
H. (2000) Relationship between intraocular pressure and obesity in Japan. International Journal of Epidemiology, 29, 661-666. http://dx.doi.org/10.1093/ije/29.4.661

[19] Ingelfinger, J.A., Mosteller, F., Thibodeau, L.A. and Ware, J.H. (1994) What are P values? In: Ingelfinger, J.A., Mosteller, F., Thibodeau, L.A. and Ware J.H., Eds., Biostatistics in Clinical Medicine, 3rd Edition, McGraw-Hill, New York, 155-173.

[20] SAS Institute Inc. (1997) SAS/STAT user's guide, version 6.12. SAS Institute Inc., Cary.

[21] Shiose, Y. (1990) Intraocular pressure: New perspectives. Survey of Ophthalmology, 34, 413-435. http://dx.doi.org/10.1016/0039-6257(90)90122-C

[22] Suh, W. and Kee, C.; Namil Study Group and Korean Glaucoma Society (2012) The distribution of intraocular pressure in urban and in rural populations: The Namil study in South Korea. American Journal of Ophthalmology, 154, 99-106. http://dx.doi.org/10.1016/j.ajo.2012.01.009

[23] Shiose, Y. (1984) The aging effect on intraocular pressure in an apparently normal population. Archives of Ophthalmology, 102, 883-887. http://dx.doi.org/10.1001/archopht.1984.0104003070302 $\underline{3}$

[24] Ganley, J.P. (1980) Epidemiological aspects of ocular hypertension. Survey of Ophthalmology, 25, 130-135. http://dx.doi.org/10.1016/0039-6257(80)90087-9

[25] Bulpitt, C.J., Hodes, C. and Everitt, M.G. (1975) Intra- ocular pressure and systemic blood pressure in the elderly. British Journal of Ophthalmology, 59, 717-720. http://dx.doi.org/10.1136/bjo.59.12.717

[26] Morgan, R.W. and Drance, S.M. (1975) Chronic openangle glaucoma and ocular hypertension: An epidemiological study. British Journal of Ophthalmology, 59, 211215. http://dx.doi.org/10.1136/bjo.59.4.211

[27] Lee, A.J., Rochtchina, E., Wang, J.J., Healey, R.R. and Mitchell, P. (2003) Does smoking affect intraocular pressure? Findings from the blue mountains eye study. Journal of Glaucoma, 12, 209-212. http://dx.doi.org/10.1097/00061198-200306000-00005

[28] Shiose, Y., Kitazawa, Y., Tsukahara, S., Akamatsu, T., Mizokami, K., Futa, R. et al. (1991) Epidemiology of glaucoma in Japan: A nationwide glaucoma survey. Japanese Journal of Ophthalmology, 35, 133-155.

[29] Collaborative Normal-Tension Glaucoma Study Group (1998) Comparison of glaucomatous progression between untreated patients with normal-tension glaucoma and patients with therapeutically reduced intraocular pressures. American Journal of Ophthalmology, 126, 487-497. http://dx.doi.org/10.1016/S0002-9394(98)00223-2

[30] Collaborative Normal-Tension Glaucoma Study Group (1998) The effectiveness of intraocular pressure reduction in the treatment of normal-tension glaucoma. American Journal of Ophthalmology, 126, 498-505. http://dx.doi.org/10.1016/S0002-9394(98)00272-4 